$\mathbb{T}$ periodica polytechnica

Chemical Engineering

$55 / 1(2011) 3+10$

doi: 10.3311/pp.ch.2011-1.01

web: http://www.pp.bme.hu/ch

(c) Periodica Polytechnica 2011

RESEARCH ARTICLE

\section{Co-treatment and utilisation of liquid pharmaceutical wastes}

Arezoo Mohammad Hosseini / Vince Bakos / Andrea Jobbágy / Gábor Tardy / Péter

Mizsey / Magdolna Makó / Antal Tungler

Received 2011-01-12

\begin{abstract}
The pharmaceutical industry produces carbon-rich liquid wastes which have been generally qualified as hazardous. A significant proportion of these carbon-rich wastes are currently sent for incineration, although they could be utilised. It was found that the majority of the liquid wastes investigated in this study could be used in biological N-removal as carbon sources for denitrification in domestic wastewater treatment, or for anaerobic biogas production. The volatile content could be separated and the solvents re-utilised, the residual toxic organic compounds could be decomposed by wet oxidation and subsequently sent for biological treatment.
\end{abstract}

\section{Keywords}

process wastewater $\cdot$ treatment $\cdot$ utilisation $\cdot$ distillation $\cdot$ denitrification $\cdot$ wet oxidation

\section{Acknowledgement}

The authors acknowledge the support NKTH under contract number NKFP06A3-VeHuHaO6, the technical assistance of Budapest Sewage Works and Geosan Ltd.

\section{Arezoo Mohammad Hosseini}

Institute of Isotopes, MTA, 1121 Budapest, Konkoly Thege Miklós út 29-33., Hungary

e-mail: delshodeh@yahoo.com

\section{Vince Bakos}

Andrea Jobbágy

Gábor Tardy

Department of Applied Biotechnology and Food Science, BME, 1111 Budapest, Gellért tér 4, Hungary

\section{Péter Mizsey}

Department of Chemical and Environmental Process Engineering, BME, 111 Budapest, Budafoki ut 8., Hungary

\section{Magdolna Makó}

Budapest Sewage Works,, 1087 Budapest, Asztalos Sándor u. 4., Hungary

\section{Antal Tungler}

Institute of Isotopes, MTA, 1121 Budapest, Konkoly Thege Miklós út 29-33., Hungary

\section{Introduction}

The pharmaceutical industry is growing worldwide and represents one of the main components of the chemical industry. However, increasing production may well be accompanied by increased amounts of by-products and wastes. Liquid wastes of high organic content - which make up a high proportion of them - have been classed as hazardous wastes and are disposed of mainly by incineration. These so-called process wastewaters (PWW) are usually aqueous solutions, and, they cannot be discharged directly into municipal sewer systems due to their high organic content. Simple dilution of these wastes is also prohibited.

A significant proportion of the carbon-rich wastes is currently sent for incineration, although they could be utilised as a carbon source for biological denitrification in domestic wastewater treatment plants, or for anaerobic biogas production. It would be possible to separate their volatile content and the solvents could be re-utilised. Residual toxic organic compounds could be decomposed by oxidation and sent for biological treatment afterwards.

So far we have found no reference in the literature [1,2] to a detailed study on mixing very large amounts of almost completely biodegradable effluents with the recalcitrant waste of the fine chemical and pharmaceutical industry. The research carried out in this area focused firstly on determining the levels of concentration of the most frequently used pharmaceuticals in surface waters [3]. The elimination ratio of some compounds in wastewater treatment plant (WWTP) and in the environment have been also studied [4,5], and in another paper [6] the authors try to follow the different processes responsible for the degradation of Carbamazepine, Clofibric Acid, Diclofenac, Ibuprofen, Ketoprofen and Naproxen in rivers and in a lake. Bouwer and coworkers [7] systematically determined the elimination efficiency (18-100\%) of WWTP for 18 pharmaceuticals and personal care products (PPCPs). Obviously the concentration of the tested compounds, including some antiseptic agents was in the $100-4000 \mathrm{ng} / \mathrm{L}$ range.

The reports on degradation studies did not focus on high concentration wastes or the systematic variation of the parameters 
affecting degradation such as the concentration of the pollutant, bacterial strains, additives and ionic strength.

The literature survey yields information about methods of incinerating these complicated wastes of varying compositions or mineralizing them in wet oxidation [8].

There are no reports, however, on low cost biological treatment of mother liquors of pharmaceutical origin, which contain organic and inorganic toxic materials. A comprehensive chemical analysis of the waste of any pharmaceutical industry is complicated to carry out due to the large number of components and it is not economically viable in industrial terms $(9,10)$.

Non-biodegradable waste generated from industrial processes can be treated by chemical oxidation, wet oxidation or with Advanced Oxidation Processes (AOP's) [11]-[14]. The PWWs generated by pharmaceuticals production often prove to be biologically recalcitrant under the current qualification procedures, due to their high organic content, molecules with aromatic rings or chlorine substituents. Therefore, they cannot be discharged directly into the municipal sewer systems and have to be treated in situ at the industrial site, or a significant proportion of them are sent for incineration [15].

A physico-chemical approach for handling these wastewaters involves separation methods that are based on the different relative volatilities of the compounds. If the contamination is more volatile than the water or forms hetero-azeotropes with it, stripping, and various kinds of distillation can be applied successfully. These physical-chemical tools have the advantage that contaminated volatile organic compounds (VOC) can be recovered and reused (16-20). If non-volatile compounds are also present, the problem requires other tools for example membrane processes or wet oxidation [20,21].

The non-volatile organic content of PWWs is very diverse, some effluents are easily biodegradable, and can be treated with activated sludge in a diluted solution. However, the wastewaters of pharmaceutical industries often contain toxic compounds which may inhibit the functioning of biomass even in very small concentrations. The most frequently used chemical treatment method for such toxic wastes is wet oxidation, which reduces the high COD level.

Biological treatment with activated sludge is the most efficient and cost-effective way of cleaning domestic wastewater. However, biological elimination of concentrated, industrial liquid wastes is not commonly applied, because of the toxic characteristics of the organic pollutants present in high concentrations. Wastes with high carbon content originating from the chemical industry usually prove to be toxic/non-biodegradable according to the currently applied qualification methods, and are therefore disposed of by expensive and often polluting technologies, e.g. incineration. On the basis of our preliminary experience we assume that well established investigation of biodegradability and appropriately designed and improved methods or processes may lead to the successful treatment of biodegradable pharmaceutical liquid wastes which contain toxic compounds in high con- centration [22].

The design and operation of biotechnological processes is mostly based on the kinetics established by Monod in 1949 [23]. This assumes that a given organic substrate asymptotically supports the growth of the microorganisms with increasing concentration (see eq. 1. and Fig. 11. However, there also exists the so called Andrews kinetics ([5] (Fig. 1], Eq. 2), developed for the biodegradation of "biodegradable, toxic" organic compounds.

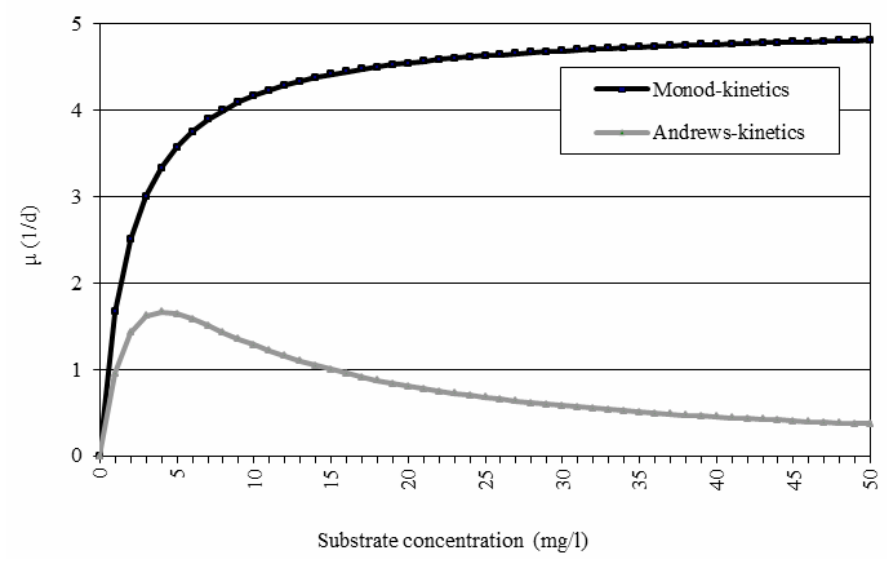

Fig. 1.

The application of Andrews' kinetics provides a new approach for the biological elimination and reuse of liquid wastes which have been regarded to date as "toxic". This type of kinetics reveals that the biodegradation of organic pollutants is a highly concentration-dependent process. Therefore, liquid toxic wastes should be biodegraded at lower concentrations.

Monod kinetics:

$$
\mu=\mu_{\max } \cdot \frac{S}{K_{S}+S}
$$

Andrews kinetics:

$$
\mu=\mu_{\max } \cdot \frac{S}{K_{S}+S+\frac{S^{2}}{K_{I}}}
$$

$\mu$

$\mu_{\max }=$ maximum specific growth rate of the biomass

$\left(\mathrm{d}^{-1}\right), \mathrm{S}=$ substrate (biodegradable pollutant) concentration $\left(\mathrm{mg} \mathrm{l}^{-1}\right)$,

$\mathrm{K}_{S} \quad=$ half saturation coefficient $\left(\mathrm{mg} \mathrm{l}^{-1}\right)$,

$\mathrm{K}_{I} \quad=$ inhibition coefficient $\left(\mathrm{mg} \mathrm{l}^{-1}\right)$

According to the Andrews model microorganisms can grow by consuming biodegradable, toxic substrates and that biodegradation is basically enhanced at low substrate concentrations. At high substrate concentrations, the inhibition and toxicity effects are expressed. Obviously, the values of the coefficients and, as a result, the shapes of the curves differ considerably depending on the nature of the substrate to be biodegraded as well as the type of biomass carrying out the degradation process.

As substrate concentration dependence is not taken into consideration in most of the common methods used for assess- 
ing biodegradability, liquid wastes which are readily biodegradable at low concentrations may be classified as toxic or nonbiodegradable. The results of the research presented in this paper indicate that liquid chemical wastes, PWWs can be treated and utilised with an appropriate combination of physical, chemical and biological operations. In order to demonstrate the validity of our assumption, several real PWWs were investigated and their COD, TOC, BOD and volatile organic content were determined, as well as the dependence of BOD on dilution with domestic wastewater. Based on the results obtained, appropriate combined treatment processes have been developed for the investigated samples, and the basic operating parameters of the different technologies (wet oxidation, biological treatment, rectification) have been determined.

\section{Experimental}

\subsection{Wastewaters and their characterization}

The process wastewater samples [15] were collected by the Budapest Sewage Works from the pharmaceutical companies located in Budapest, all of which are interested in the sustainable disposal of their liquid wastes. Each sample originates from a production technology of a given drug molecule or intermediate. They were treated as "black boxes", without detailed chemical analysis; their volatile organic content, physical and chemical characteristics, COD, TOC and BOD values were measured, and their anaerobic digestion and oxidation properties determined.

\subsection{Chemical characterization, COD and TOC measure- ments}

COD was determined by the standard dichromate method. The TOC was determined by a Shimadzu TOC analyzer whose operation was based on catalytic combustion and non-dispersive infrared (NDIR) gas analysis. The following parameters were measured (some of these only for selected PWWs): $\mathrm{pH}$, total salt content, ammonia, TKN (total Kjeldahl nitrogen), dry organic material.

\subsection{Biodegradation characterization}

The behaviour of the PWWs was investigated by aerobic respirometric tests and anaerobic digestion tests, while toxicity was estimated on the basis of sludge respirometry and batch digestion experiments were carried out by measuring residual COD. The aerobic respirometric tests were carried out in a WTW OxiTop device, measuring the oxygen consumption over 10 days $\left(\mathrm{BOD}_{10}\right)$. The dilution of the tested PWW was conducted until $800 \mathrm{mg} / \mathrm{L}$ oxygen consumption, calculated from COD values. For dilution two peptone solutions were used as basis wastewaters in concentrations of 25 and $100 \mathrm{mg} / \mathrm{L} \mathrm{COD,}$ which also contained $\mathrm{NH}_{4} \mathrm{Cl}, \mathrm{K}_{2} \mathrm{HPO}_{4}, \mathrm{KH}_{2} \mathrm{PO}_{4}, \mathrm{MgCl}_{2}$ and $\mathrm{CaCl}_{2}$. Released water from the secondary clarifier of the SouthPest Wastewater Treatment Plant (WWTP) was used for seeding (seeding was provided by the residual suspended biomass). Oxygen consumption coupled with nitrification was eliminated by adding allyl thiourea. In the figures (Figs. 2, 3, 4, with respirometric curves the oxygen consumption is given in $\mathrm{mg} / \mathrm{L}$ units calculated for the non-diluted PWW.

$\mathrm{BOD}_{5}$ was measured according to DIN EN 1899-1, also with an OxiTop device (Fig. 5.b). Denitrification was tested in anoxic conditions in a zero gas-space $2.5 \mathrm{~L}$ batch reactor. $1.2 \mathrm{~g} / \mathrm{L}$ activated sludge was used as the seeding biomass, while the water of the final aerobic basin of the South-Pest WWTP was used as the diluting medium. The COD concentration of the investigated waste was $200 \mathrm{mg} / \mathrm{L}$, the nitrate concentration $400 \mathrm{mg} / \mathrm{L}$. Samples were withdrawn every 30 minutes over 9 hours and their nitrate, nitrite and COD values were measured.

\subsection{Determination of the volatile organic content}

The volatile organic content of the process wastewaters was measured with a distillation probe and subsequent GC analysis, where the most common components (methanol, ethanol, ethyl acetate, acetone, etc.) could be identified and their concentration determined. In addition, initial batch rectification experiments were carried out for every PWW. When the batch rectification resulted in significant COD reduction the PWWs were further investigated. The PWWs of high VOC were also rectified in continuous mode in a pilot plant laboratory column of 14 theoretical plates.

\subsection{Oxidation procedures}

The non-basic wastewaters $(\mathrm{pH}<8)$ were basified before oxidation with a solution of $20 \% \mathrm{NaOH}$. The samples were oxidized in $850 \mathrm{ml}$ stainless steel high pressure autoclaves equipped with magnetic stirrers (rpm 700), at temperatures up to $250^{\circ} \mathrm{C}$ and 50 bar total pressure. After $\mathrm{pH}$ adjustments, the wastewater samples were loaded into the autoclave, pressurized with oxygen and heated to the desired temperature, with total pressure regulated to 50 bar by refilling the autoclave with oxygen, after which samples were taken and subsequently analyzed.

\section{Results and discussion}

The measured parameters and biodegradation characteristic values of the treated PWWs are summarized in Tables 1 and 2

The PWWs tested represent a large variety of liquid wastes of the pharmaceutical industry, thus their organic and inorganic content were rather diverse (COD range of the investigated samples: $1096-751800 \mathrm{mg} / \mathrm{L})$. The biodegradability of the samples also proved to be highly variable (the BOD/COD ratios of the samples were between 2-96\%). Thus, it is reasonable to assume that these PWWs require different treatment methods for example mixing of the well biodegradable waste No. 5227 with waste No. 4982, which proved to be toxic at any dilutions must be avoided, as it can hinder the biodegradability of the whole mixture. The treatment has to be preceded by the determination of the properties of the given PWW, in order to provide sufficient information for the producing company to be able to properly decide about its fate. 
Tab. 1. Parameters of tested PWWs

\begin{tabular}{|c|c|c|c|c|c|c|c|c|c|c|c|}
\hline \multirow[t]{2}{*}{$\begin{array}{l}\text { Sample } \\
\text { No. }\end{array}$} & \multirow{2}{*}{$\begin{array}{l}\text { COD } \\
\mathrm{mg} / \mathrm{L}\end{array}$} & \multirow{2}{*}{$\begin{array}{c}\text { TOC } \\
\mathrm{mg} / \mathrm{L}\end{array}$} & \multirow{2}{*}{$\begin{array}{l}\mathrm{BOD}_{10} \\
\mathrm{mg} / \mathrm{L}\end{array}$} & \multirow{2}{*}{$\begin{array}{l}\text { Adapt. time } \\
\text { days }\end{array}$} & \multirow{2}{*}{$\begin{array}{l}\text { Volatile } \\
\text { content }\end{array}$} & \multirow{2}{*}{$\mathrm{pH}$} & \multirow{2}{*}{$\begin{array}{c}\text { TKN } \\
\mathrm{mg} / \mathrm{L}\end{array}$} & \multirow{2}{*}{$\begin{array}{l}\mathrm{NH}_{4}^{+}-\mathrm{N} \\
\mathrm{mg} / \mathrm{L}\end{array}$} & \multirow{2}{*}{$\begin{array}{l}\text { Total salt } \\
\mathrm{g} / \mathrm{L}\end{array}$} & \multicolumn{2}{|c|}{$\begin{array}{l}\text { Efficiency of oxidation } \\
\star \star \star \star\end{array}$} \\
\hline & & & & & & & & & & $\begin{array}{l}\text { COD } \\
\text { decrease \% }\end{array}$ & $\begin{array}{l}\text { TOC } \\
\text { decrease \% }\end{array}$ \\
\hline 4693 & 117000 & 41200 & 98418 & 5.5 & 2.8 & 14 & & & & 30 & 33 \\
\hline 4694 & 68000 & 20090 & 24738 & 3.5 & 0.28 & 14 & & & & 40 & 27 \\
\hline 4695 & 80000 & 25070 & 49298 & 1.5 & 0.9 & 14 & & & & 38 & 27 \\
\hline 4982 & 81715 & 23270 & 1838 & 5.0 & 0.12 & 8.4 & 5874 & $1215^{\star \star \star}$ & 175 & 49 & 25 \\
\hline $\begin{array}{l}4983 \\
d 10 x\end{array}$ & 751800 & 208000 & 721780 & 0.5 & $57^{*}$ & 9 & 309 & 9 & 1.1 & 15 & 7 \\
\hline 5226 & 39750 & 11600 & 36458 & 0.5 & 2.6 & 11 & & & & 49 & 34 \\
\hline $\begin{array}{l}5227 \\
d 3 x\end{array}$ & 80236 & 26580 & 77358 & 0.5 & 4.4 & 6 & 67 & 6.7 & - & 41 & 7 \\
\hline $\begin{array}{l}600 \\
d 5 x\end{array}$ & 525620 & 134700 & 410665 & 4.0 & $32.4^{* *}$ & 5 & & & & 8 & 2.5 \\
\hline 602 & 1096 & 437 & 906 & 2.0 & & 7 & & & & 60 & 55 \\
\hline 5691 & 16005 & 8267 & 8303 & 1.0 & & 8 & & & & 58 & 54 \\
\hline 5692 & 63079 & 24690 & 28957 & 0.0 & & 14 & & & & 40 & 33 \\
\hline 5693 & 65471 & 19370 & 40537 & 3.5 & & 7 & & & & 32 & 28 \\
\hline $\begin{array}{l}5797 \\
\text { d10x }\end{array}$ & 178180 & 52850 & 36883 & 3.5 & & 1 & 15.2 & 0.2 & 15.8 & 36 & 20 \\
\hline $\begin{array}{l}6367 \\
\text { d10x }\end{array}$ & 235220 & 89380 & 141033 & 2.0 & 1.4 & 10 & & & & 25 & 5 \\
\hline
\end{tabular}

ethanol, ${ }^{\star *}$ methanol, ${ }^{\star \star \star}$ ammonium chloride, ${ }^{\star \star \star \star} 250^{\circ} \mathrm{C}, 50$ bar, 5 hours, $\mathrm{d} 3,5,10 x$ means diluted in the given ratio

Tab. 2. Biodegradation characteristics of PWW

\begin{tabular}{|c|c|c|c|c|c|c|}
\hline \multirow{2}{*}{$\begin{array}{l}\text { Sample } \\
\text { No. }\end{array}$} & \multicolumn{4}{|c|}{$\mathrm{BOD} / \mathrm{COD} \%$} & \multirow{2}{*}{$\begin{array}{l}\text { Denitrification capacity } \\
\text { with respect to COD }\end{array}$} & \multirow{2}{*}{$\begin{array}{l}\text { Anaerobic digestion effi } \\
\text { ciency }\end{array}$} \\
\hline & original & $\begin{array}{l}\text { after } \\
\text { oxidation }\end{array}$ & $\begin{array}{l}\text { with basis } \\
\text { wastewater }\end{array}$ & $\begin{array}{l}\text { after oxidation } \\
\text { with basis } \\
\text { waste water }\end{array}$ & & \\
\hline 4693 & 84 & 65 & 91 & 80 & & \\
\hline 4694 & 36 & 65 & 66 & 86 & & \\
\hline 4695 & 62 & 81 & 75 & 94 & & \\
\hline 4982 & 2 & 23 & 0 & 34 & no & no \\
\hline 4983 & 94 & 98 & 94 & 100 & $\operatorname{good}(\sim 100 \%)$ & $\begin{array}{l}\text { added in }>5 \mathrm{v} / \mathrm{v} \% \text { it is } \\
\text { toxic }\end{array}$ \\
\hline 5226 & 92 & 65 & 94 & 93 & $\operatorname{good}(\sim 100 \%)$ & \\
\hline 5227 & 96 & 89 & & & & $\begin{array}{l}\text { added in }<10 \mathrm{v} / \mathrm{v} \% \text { it is } \\
\text { digestible }\end{array}$ \\
\hline 600 & 78 & 100 & 95 & 100 & & \\
\hline 5692 & 46 & 71 & 91 & 98 & & \\
\hline 5693 & 62 & 74 & 94 & 93 & & \\
\hline 5797 & 21 & 98 & 28 & 100 & $\begin{array}{l}\text { doubled upon oxidation } \\
(30 \rightarrow 60 \%)\end{array}$ & $\begin{array}{l}\text { non toxic } \\
\text { good }\end{array}$ \\
\hline 6367 & 60 & 76 & 90 & 86 & & \\
\hline
\end{tabular}


Tab. 3. Atmospheric rectification (in a column with 14 theoretical plates) results of PWWs

\begin{tabular}{lll}
\hline Sample No. & 4983 & 600 \\
\hline Feed composition v/v\% & 57 ethanol, 43 water, & 32 methanol, 1 acetone, 67 water \\
amount L/hour & 0.45 & 0.37 \\
\hline Reflux ratio & 5 & 3 \\
\hline Location of feed & middle of column & middle of column \\
\hline Dist. composition v/v\% & 90 ethanol, 10 water & 96 organic \\
amount L/hour & 0.28 & 0.13 \\
\hline Bottom am. L/hour & 0.17 & 0.24 \\
volatile content v/v\% & 210 ppm ethanol & 1460 ppm methanol \\
COD mg/L & 2500 & 4400 \\
BOD/COD \% & 95 & 85 \\
\hline Remarks & crystalline precipitation in the boiler & brown colored bottom product, solution with crystals, sed- \\
& & imentation is possible \\
\hline
\end{tabular}

Based on the measurement results the following observations were made:

1 PWWs No. 4983 and 600 have high COD contents (751800 $\mathrm{mg} / \mathrm{L}$ and $525620 \mathrm{mg} / \mathrm{L}$, respectively) deriving basically from their high volatile (ethanol and methanol) content, which can be recovered with rectification and reused (see Table 3 ).

This operation may be necessary as the high ethanol and methanol content decreases the rate of oxidation and can be toxic at higher concentrations for anaerobic digestion as well. The organic content of the bottom product of the rectification (which needs further treatment), is very low (COD of No. 4983: $2500 \mathrm{mg} / \mathrm{L}$ and No. 600: $4400 \mathrm{mg} / \mathrm{L}$ ) compared to the COD content of the original wastes. Continuous pilot scale denitrification experiment proved that the PWW with high ethanol content (No. 4983) can be mixed with domestic wastewater and utilised biologically as an external carbon source for denitrification without pre-treatment. Economic considerations should determine which kind of treatment is more appropriate.

2 Based on respirometric measurements it can be suggested that PWW No. 4982 without pre-treatment is toxic for biodegradation even having diluted by domestic wastewater (Fig. 2). As biodegradation without pretreatment is not an option to decrease this wastewater (4892) toxicity, it should be oxidized although it is very corrosive under oxidation conditions because of its high ammonium chloride content. In this case the incineration may remain the optimal solution for its disposal.

3 The majority of PWWs are biodegradable (Fig. 3), which means that the organic content of these wastes can be used as a carbon source for denitrification in appropriate conditions. The BOD/COD ratio of sample No. 4695 without pretreatment is $62 \%$. With the wet oxidation pre-treatment this ratio can be raised to $81 \%$ (see Table 2), effectively decreasing the amount of the non-biodegradable residue. However during the pretreatment of the PWW a part of the originally

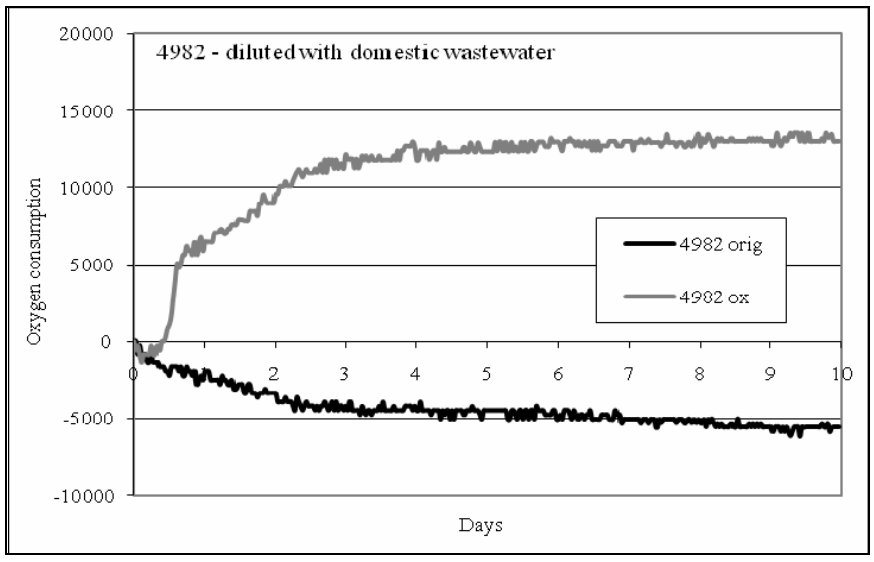

Fig. 2. Oxygen consumption of PWW 4982 (original and oxidized) diluted with domestic wastewater

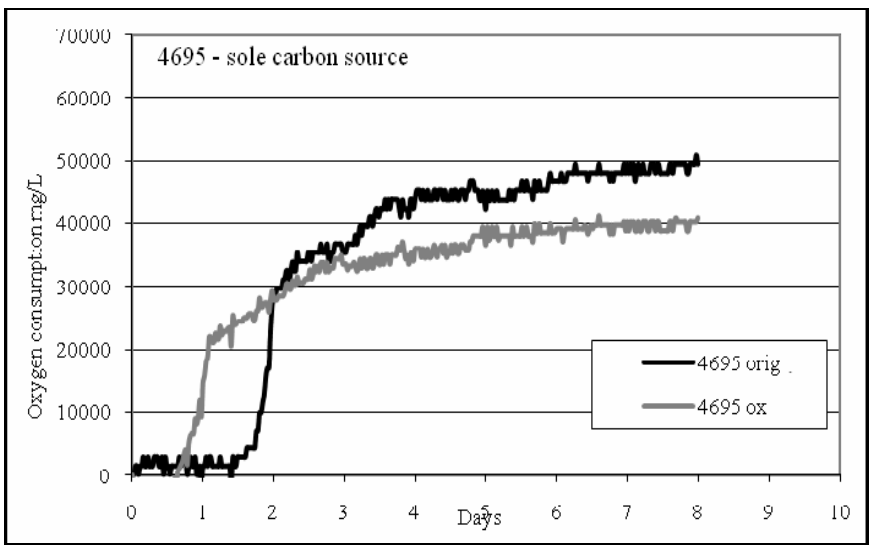

Fig. 3. Oxygen consumption of PWW 4695 as sole carbon source

biodegradable organics are also oxidized, thus the total biodegraded amount of organic compounds decreased, that results in $\sim 40000 \mathrm{mg} / \mathrm{l}$ oxygen consumption instead of the original $50000 \mathrm{mg} / \mathrm{L}$.

The original sample No. 5797 proved to be poorly biodegradable (Fig. 4, the BOD/COD ratio was $21 \%$ ), however, after pre-treating the sample with wet oxidation, the biodegradability was greatly improved (the BOD/COD ratio increased to 


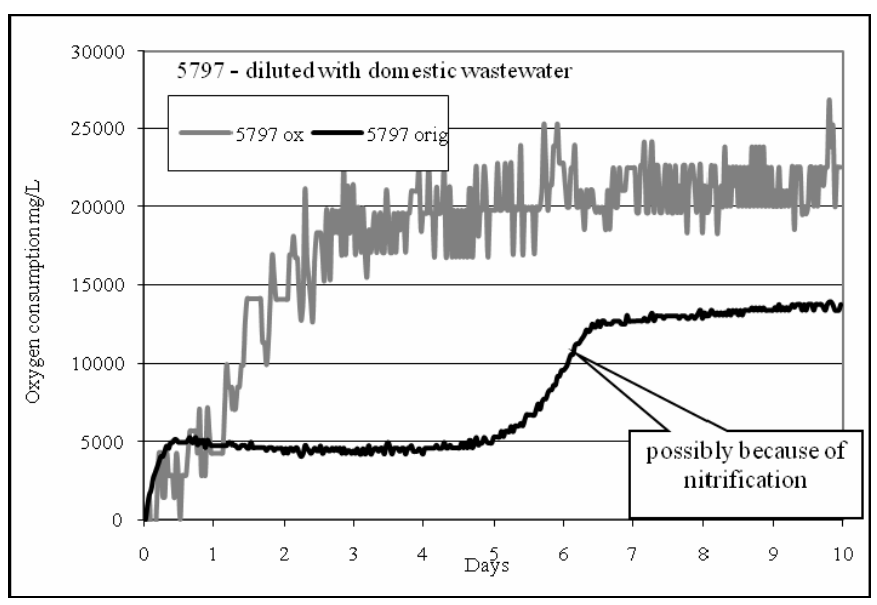

Fig. 4. Oxygen consumption of PWW 5797 diluted with domestic wastewater

$98 \%)$.

BOD5 of 5797 in different dilution with domestic wastewater

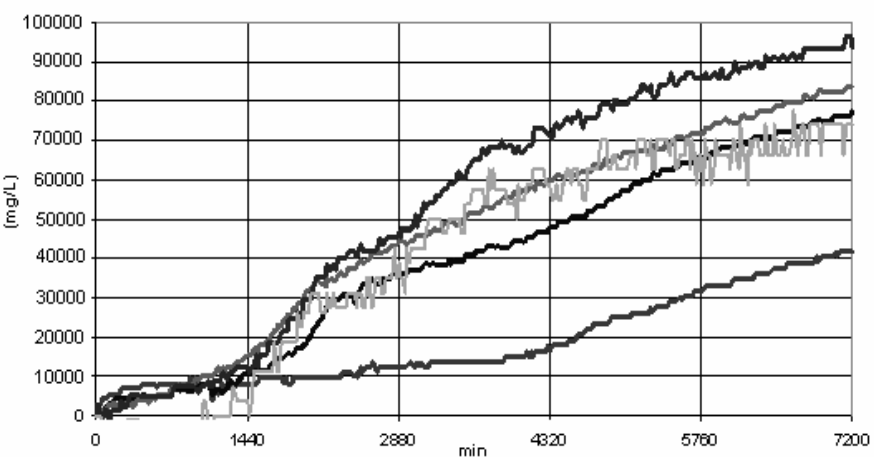

Fig. 5.a. Oxygen consumption of PWW 5797 diluted with domestic wastewater in different ratio

BOD5 of 4983 in different dilution with domestic wastewater

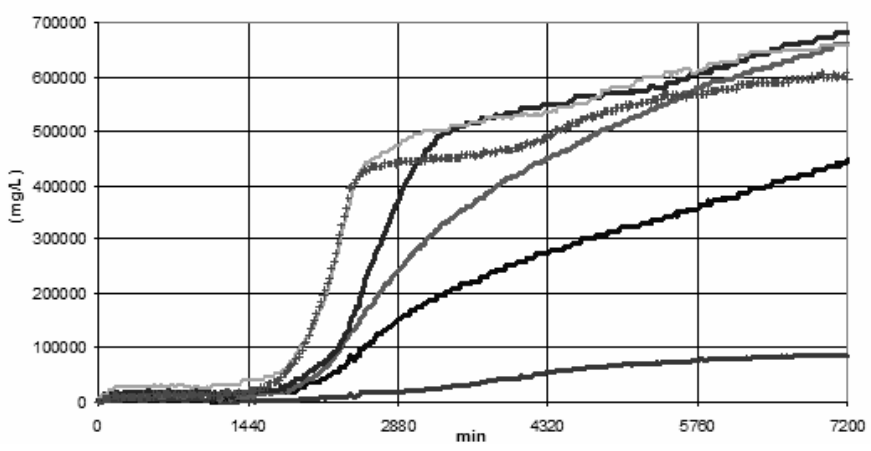

Fig. 5.b. Oxygen consumption of PWW 4983 diluted with domestic wastewater in different ratio

Biodegradation of samples No. 5797 and No. 4983 showed strong concentration-dependence

(Fig. 5.a 5.b), suggesting that although these wastes are not biodegradable in high concentration, with appropriate dilution they can be utilized as external carbon sources for denitrification.

4 The wet oxidation efficiency (based on oxidation experiments conducted for 5 hours at $250^{\circ} \mathrm{C}, 50$ bar total pressure, which means $\sim 10$ bar oxygen partial pressure, in a batch reaction) is diverse, the percentage of COD decrease falls between 8 and 60 (see Table 11). The two lowest conversions were obtained by the oxidation of the two PWWs with the highest COD values, due to their high volatile organic solvent content. It was suggested in point 1 that distillation is needed before using any other treatment method.

Detailed respirometric investigation clearly verified our assumption that most PWWs are biodegradable at least after dilution with domestic wastewater at various ratios (Fig. 5.b. The exception is PWWs No. 4982 (Fig. 2), which is not degradable in its original state, but becomes degradable after oxidation.

On the basis of these results a combined treatment method of the different PWWs has been developed, resulting in Scheme 1. The scheme summarizes the possible means of treatment and gives guidelines for choosing the appropriate treatment method for different PWWs. Two examples demonstrate how its guidance can be used: Sample No. 4983 can be treated in two ways: it can be used in denitrification or its volatile content can be distilled and the distillation residue can subsequently be mixed with domestic wastewater and be treated with activated sludge. No. 4982 has no volatile content and is not biodegradable, so it has to be oxidized first, thereafter it can be biodegraded. The other PWWs are biodegradable in their original form or at least when diluted with domestic wastewater.

\section{Conclusion}

It has been shown that the biological and physico-chemical co-treatment of PWWs of the pharmaceutical industry can be effectively accomplished, and the majority of the PWWs tested proved to be biodegradable when appropriately diluted with domestic wastewater. The exceptions are the PWWs with high volatile organic solvent content and the toxic ones, with the latter being lethal for the activated sludge even in high dilution. These PWWs must not be mixed with the others, but the high volatile content should be removed by rectification or stripping. After removing their volatile content, the remaining materials of low COD are biodegradable and the solvents recovered can be utilized. The toxic waters require wet oxidation, which does not have to be carried out to a complete mineralization, it is enough if the toxic components are degraded. The partly oxidized PWWs contain biodegradable compounds, usually small carbon atom number carboxylic acids such as acetic acid, which are an excellent carbon source for denitrification.

Complex physical, chemical and biological treatment offers a sustainable and competitive alternative to incineration. In order to determine a safe treatment method, the appropriate combination of the aforementioned techniques and the detailed characterization of the PWWs will be needed, including the quantification of their biodegradability when diluted with domestic wastewater at different ratios. 


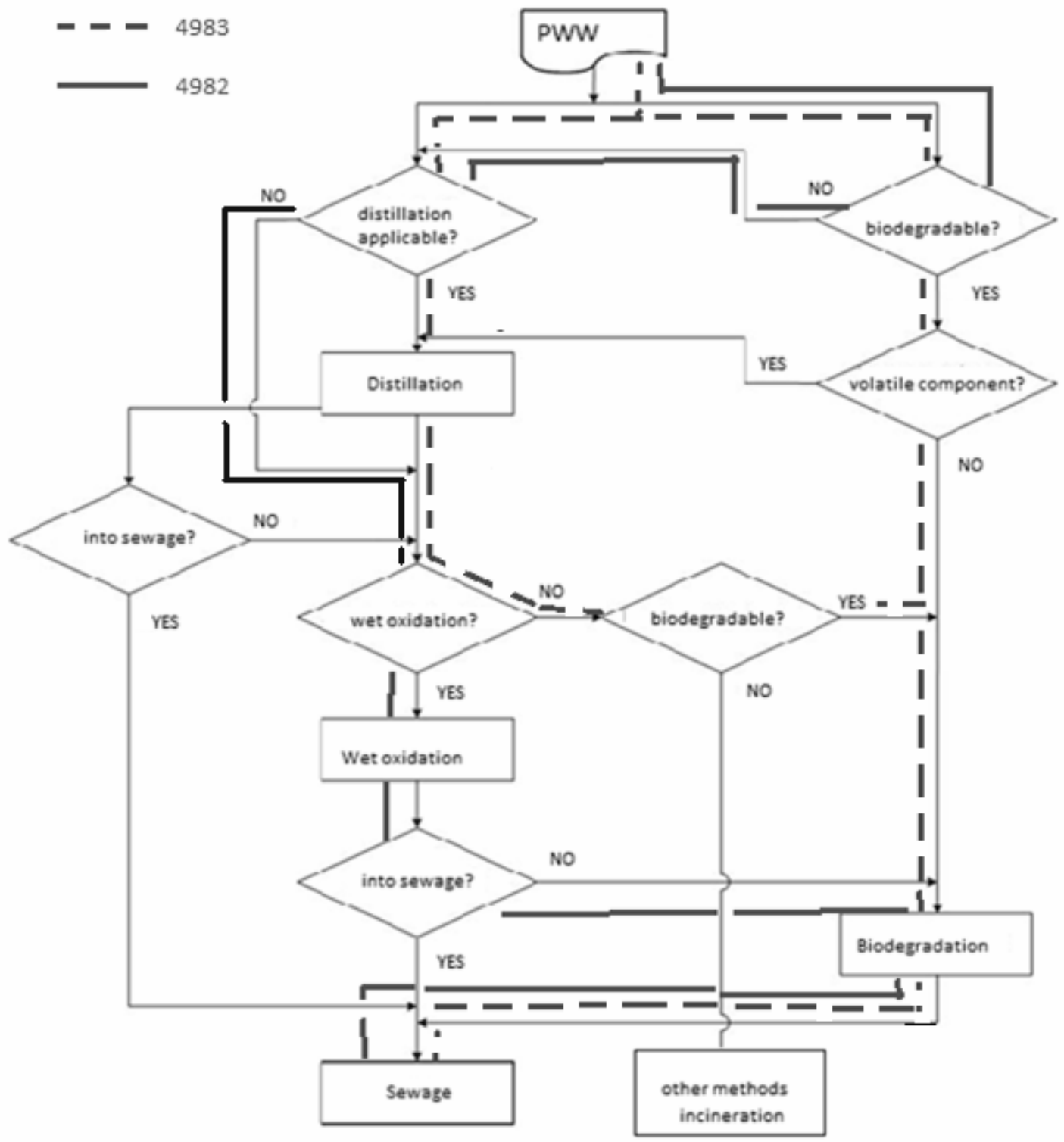

Fig. 6. Treatment alternatives of PWWs of pharmaceutical origin

\section{References}

1 Roques H, Chemical Water Treatment, Principles and Practice, VCH Pub, New York 10010 NY, USA, 2001

2 Masango $\mathbf{P h}$, Cleaner production of essential oils by steam distillation, J. Clean. Prod 13 (2005), 833-839.

3 Kümmerer K, Pharmaceuticals in the Environment, Sources, Fate, Effects and Risks, Springer-Verlag, Berlin, 2001.

4 Ternes Th A, Occurrence of drugs in German sewage treatment plants and rivers, Water Res. 32 (1998), 3245-3260.

5 Buser H R, Müller M D, Theobald N, Occurrence of the pharmaceutical drug clofibric acid and the herbicide mecoprop in various Swiss lakes and the North Sea, Environ. Sci. Technol 32 (1998), 188-192.

6 Tixier C, Singer H P, Oellers S, Müller S R E, Occurrence and Fate of Carbamazepine, Clofibric Acid, Diclofenac, Ibuprofen, Ketoprofen, and Naproxen in Surface Water, Environ. Sci. Technol 379 ( 2003), 1061-1068.

7 Yu J T, Bouwer E J, Coelhan M, Occurrence and biodegradability studies of selected pharmaceuticals and personal care products in sewage effluent, Agr. Water Manage 86 (2006), 72-80.

8 Herrmann J M, Guillard C, Pichat P, Heterogeneous photo-catalysis: An emerging technology for water treatment, Catal. Today 17 ( 1993), 7-20.

9 Stumm W, Morgan J, Aquatic Chemistry. J. Wiley, 1991.
10 Nadtochenko V, Kiwi J, Primary Photochemical Reactions in the PhotoFenton System with Ferric Chloride. 1. A Case Study of Xylidine Oxidation as a Model Compound, Environ. Sci. Technol 32 (1998), 3273-3281.

11 Emanuel M, Denisov T, Mazyus R, Liquid phase oxidation of hydrocarbons, Plenum Press, New York, 1967.

12 Freedman L, Hydrocarbon Processing, Wiley, New York, 1993.

13 Ollis F, Al-Ekabi H, Photocatalytic Purification and Treatment of Water and Air., Elsevier, Amsterdam, 1994.

14 Markard J, Stadelmann M, Truffer B, Prospective analysis of technological innovation systems: Identifying technological and organizational development options for biogas in Switzerland, Res. Policy (2009), 38655-667.

15 Ullmann's Encyclopedia of Industrial Chemistry, Wiley-VCH Verlag GmbH \& Co. KGaA.) Wastewater (Walter Simmler, Bayer AG, Leverkusen, Federal Republic of Germany, 2002.

16 Lucia A, Finger E J, Co-solvent selection and recovery, Adv. Environ. Res 8 (2004), 197-211.

17 Dursun D, Sengul F, Waste minimization study in a solvent-based paint manufacturing plant, Resources, Conserv. Recycling 47 (2006), 316-331.

18 Mizsey P, Koczka K, Tungler A, Technológiai hulladékvizek kezelése fiziko-kémiai módszerekkel, Magy. Kém. Foly. 114 (2008), no. 3, 107-113. 
19 Mizsey P., Koczka K., New area for distillation: wastewater treatment, Per. Pol. Chem. Eng. 54 (2010), no. 1, 41-45.

20 Blöcher C, Dorda J, Mavrov V, Chmiel H, Lazadiris N K, Matis K. A., Hybrid flotation-membrane filtration process for the removal of heavy metal ions from wastewater, Water Res. 37 (2003), 4018-4026.

21 Cséfalvay E, Pauer V, Mizsey P, Experimental Data Based Modelling and Simulation of Isopropanol Dehydration by Pervaporation 229 (2008), 94108.

22 Smets B F, Jobbágy A, Cowan R M, Grady C P L Jr., Evaluation and respirometric data: identification of featrures that are perclude data fitting with existing kinetic expressions, Ecotox. Environ. Safe 33 (1996), 88-99.

23 Monod J, The growth of bacterial cultures, Ann. Rev. Microbiol 3 (1949), 371-394.

24 Andrews J F A, A mathematical model for the continuous culture of microorganisms utilizing inhibitory substrates, Biotechnol. Bioengin 10 (1968), 707-723. 